University of Nebraska - Lincoln

DigitalCommons@University of Nebraska - Lincoln

Faculty Publications from the Harold W. Manter Laboratory of Parasitology

4-1997

\title{
A Guideline for the Preparation of Species Descriptions in the Eimeriidae
}

Donald Duszynski

University of New Mexico, eimeria@unm.edu

Patricia G. Wilber

University of New Mexico

Follow this and additional works at: https://digitalcommons.unl.edu/parasitologyfacpubs

Part of the Parasitology Commons

Duszynski, Donald and Wilber, Patricia G., "A Guideline for the Preparation of Species Descriptions in the Eimeriidae" (1997). Faculty Publications from the Harold W. Manter Laboratory of Parasitology. 156. https://digitalcommons.unl.edu/parasitologyfacpubs/156

This Article is brought to you for free and open access by the Parasitology, Harold W. Manter Laboratory of at DigitalCommons@University of Nebraska - Lincoln. It has been accepted for inclusion in Faculty Publications from the Harold W. Manter Laboratory of Parasitology by an authorized administrator of DigitalCommons@University of Nebraska - Lincoln. 


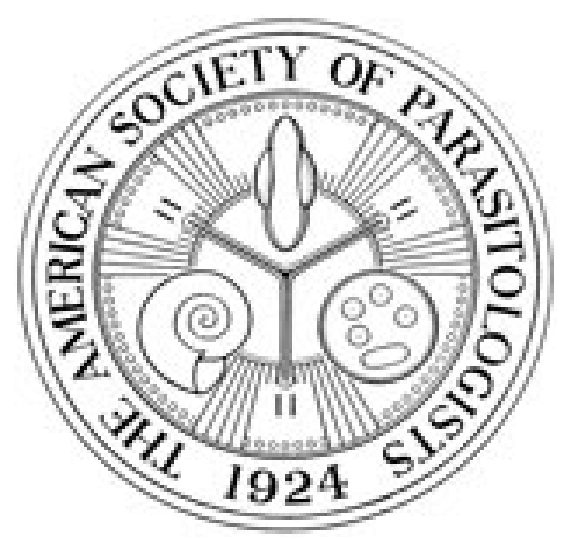

A Guideline for the Preparation of Species Descriptions in the Eimeriidae Author(s): Donald W. Duszynski and Patricia G. Wilber

Source: The Journal of Parasitology, Vol. 83, No. 2 (Apr., 1997), pp. 333-336

Published by: The American Society of Parasitologists

Stable URL: http://www.jstor.org/stable/3284470

Accessed: 20/04/2010 00:03

Your use of the JSTOR archive indicates your acceptance of JSTOR's Terms and Conditions of Use, available at http://www.jstor.org/page/info/about/policies/terms.jsp. JSTOR's Terms and Conditions of Use provides, in part, that unless you have obtained prior permission, you may not download an entire issue of a journal or multiple copies of articles, and you may use content in the JSTOR archive only for your personal, non-commercial use.

Please contact the publisher regarding any further use of this work. Publisher contact information may be obtained at http://www.jstor.org/action/showPublisher?publisherCode=asp.

Each copy of any part of a JSTOR transmission must contain the same copyright notice that appears on the screen or printed page of such transmission.

JSTOR is a not-for-profit service that helps scholars, researchers, and students discover, use, and build upon a wide range of content in a trusted digital archive. We use information technology and tools to increase productivity and facilitate new forms of scholarship. For more information about JSTOR, please contact support@jstor.org.

The American Society of Parasitologists is collaborating with JSTOR to digitize, preserve and extend access to The Journal of Parasitology. 


\title{
A GUIDELINE FOR THE PREPARATION OF SPECIES DESCRIPTIONS IN THE EIMERIIDAE
}

\author{
Donald W. Duszynski and Patricia G. Wilber \\ Department of Biology, The University of New Mexico, Albuquerque, New Mexico 87131
}

\begin{abstract}
Members of the suborder Eimeriina (phylum Apicomplexa: class Sporozoea: order Eucoccidiorida) have complex 1 or 2 host life cycles that involve endogenous development in the tissues of vertebrates or invertebrates and exogenous development in an oocyst, usually outside the host(s). Because tissue stages are logistically difficult or even impossible to obtain in natural (wild) host-parasite systems, the vast majority $(>98 \%)$ of species in this parasite complex are known only from the structure of their sporulated oocyst. Unfortunately, the quality of these species descriptions is uneven because no guidelines are available for workers in the field to follow. Here we propose a specific set of guidelines for the preparation of species descriptions of coccidia based predominently on the structure of the sporulated oocyst, because the oocyst is the most readily available stage in the life cycle. In addition, we emphasize that ancillary data be incorporated whenever possible with the species description; these data may include, but are not limited to, ecological parameters, prevalence, seasonal data, and the deposition of both host symbiotypes and parasite hepantotypes (=phototypes) into accredited museums so that accurate identification of both host and parasite material can be assured in perpetuity. And finally, if oocysts are collected in pure suspension, that is, if only one coccidian species (morphotype) is present in the sample, then some oocysts should be saved in $70 \%$ ethanol and archived in an accredited museum in the event that future workers might wish to amplify and, later, sequence the parasite's DNA.
\end{abstract}

Ultimately, the value and robustness of any classification scheme, from the species to all higher taxonomic categories, rests on the foundation of the species description. Within the protozoan phylum Apicomplexa Levine, 1970, about one-third of the approximately 5,000 described species reside in a single family, Eimeriidae, and about $98 \%$ of these species are known only from 1 life-cycle stage, the sporulated oocyst, which has a limited number of structural characters. Unfortunately, the fewer the number of morphological characteristics in a group of parasites, the more bothersome the species problem becomes, and within the Eimeriidae it is not possible to delimit what is a species to everyone's satisfaction. Thus, if the taxonomy of this group is to be useful for higher level examination (systematic, phylogenetic, zoogeographic, host specificity, and other studies), the taxonomic procedure followed in documenting the existence of new eimeriid species must not only be consistent, but it should follow the intent, if not the letter, of the International Code of Zoological Nomenclature. As Ernst Mayr (1957) clearly pointed out, "It is unrewarding to pursue the problem of host specificity" (or other biological problems) "unless one's conclusions are based on sound systematics and reliable host records."

After working on the taxonomy of coccidia over the past 2 decades, it has become painfully clear that procedures used by those who describe new species, in the past and up to the present, are not consistent in many ways with the International Code. For example, the Code explicitly recommends the designation of type specimens for new species, but a type tradition had been lacking among taxonomists working with the Eimeriidae until Bandoni and Duszynski (1988) provided a framework to help resolve this problem. Lom and Arthur (1989) recognized a similar deficiency in the way myxosporean species were described and they published, "A guideline for the preparation of species descriptions in Myxosporea." In their paper, they pointed out the many difficulties created for later workers

Received 15 July 1996; revised 21 October 1996; accepted 21 October 1996. by published descriptions of poor quality and emphasized that such practice, "ridicules taxonomic research in this group in the eyes of other parasitologists." The same also can be said for the taxonomy of species within the Eimeriidae.

Therefore, our objectives in this paper are to emphasize and encourage greater precision in the description of new coccidian species when only the sporulated oocyst is available, and establish certain minimal guidelines for proper description of these oocysts in the hope these guidelines will be followed both by those describing and naming new coccidians and by the editors of the journals who consider these papers for publication.

\section{SAVING, STORING, AND PREPARING OOCYSTS FOR OBSERVATION}

Before oocysts can be studied critically, they must be properly maintained to keep them viable so that their structural integrity remains intact. In our experience, oocysts from different vertebrate host species fall into two groups, which, of necessity, need to be handled differently when collected under field conditions.

\section{Oocysts from birds, mammals, and terrestrial invertebrates and reptiles}

These oocysts keep best when fresh feces are placed directly into $2-2.5 \%$ aqueous $(\mathrm{w} / \mathrm{v})$ potassium dichromate $\left(\mathrm{K}_{2} \mathrm{Cr}_{2} \mathrm{O}_{7}\right)$ in a ratio of 1 volume of feces : $\geq 5$ volumes $\mathrm{K}_{2} \mathrm{Cr}_{2} \mathrm{O}_{7}$. In field collections, either snap-cap or screw-cap 16-25-ml vials work well, but one should not fill the vial all the way to the top; leave a layer of air between the top of the feces-dichromate mixture and the cap to allow the oocysts some atmospheric oxygen. Unfortunately, other solutions for feces, for example, $2 \%(\mathrm{v} / \mathrm{v})$ aqueous sulfuric acid (see Wash et al., 1985) or common laboratory fixatives for oocysts (see Duszynski and Gardner, 1991), have proven unsatisfactory either for keeping oocysts viable or for preserving them as types. 


\section{Oocysts from amphibians, fish, and aquatic invertebrates and reptiles}

These oocysts often are very thin walled and fragile and sometimes prove difficult to sporulate. When examining hosts from freshwater environments, fresh mucus and feces from the intestinal tract should be placed in vials with tap water or with filtered river water at room temperature. Likewise, mucus and gut contents of marine animals should be placed in containers with filtered seawater. These fecal-water solutions must be supplemented with $200 \mathrm{IU}$ penicillin $\mathrm{G} / \mathrm{ml}, 200 \mu \mathrm{g}$ streptomycin $/ \mathrm{ml}$, and 0.5 $\mu \mathrm{g}$ Fugizone/ml (see Upton et al., 1988; Molnár, 1996).

\section{Laboratory processing}

Upon return to the laboratory, the fecal-dichromate or fecalwater-antibiotic mixtures should be placed into a petri dish, any fecal pellets should be broken, and the fecal material spread out in the dish and covered (Duszynski and Conder, 1977). The petri dishes generally should be maintained at room temperature (20-23 C) for 7-10 days, which will allow any oocysts present to sporulate. Fecal-dichromate mixtures (terrestrial hosts) should not be refrigerated prior to the sporulation process as, in our experience, this will interfer with sporulation success. However, oocysts of some marine fishes were found to sporulate adequately only when the fecel-supplemented seawater mixture was placed on ice for 7-8 days (Upton et al., 1988); in this instance, the oocyst wall ruptured shortly after sporulation, releasing free sporocysts. In most species, however, after about 7-10 days, the mixture can be washed from the petri dish with clean $2 \% \mathrm{~K}_{2} \mathrm{Cr}_{2} \mathrm{O}_{7}$ into a screw-cap jar (baby food jars work well) filled only about half way and then put into a standard refrigerator (4-7 C) until the material can be examined (sugar flotation) for the presence of oocysts. In our experience, oocysts of terrestrial vertebrates can remain viable, or at least structurally intact, in the refrigerator for 3-4 yr, whereas oocysts of certain fish coccidians (Upton et al., 1988; Molnár, 1996) may deteriorate soon after sporulation and die within a few days or weeks. Thus, it is probably best to study and document the structure of sporulated oocysts as soon as possible after they are sporulated.

Sporulated oocysts are best separated from the dichromatefecal mixture by suspending an aliquot (1-3 ml) from the sample in 14-12 ml of modified Sheather's (Sheather, 1923) sugar flotation solution ( $500 \mathrm{~g}$ sucrose, $350 \mathrm{ml}$ tap water, $5 \mathrm{ml}$ phenol) via centrifugation ( $5 \mathrm{~min}$ at $1,500 \mathrm{rpm}[=225 \mathrm{~g}])$. It is important to use only number $1,18-\mathrm{mm}^{2}$, coverslips on top of the $15-\mathrm{ml}$ centrifuge tubes (those with a smooth, beaded edge work best) as this reduces the surface area that needs to be scanned for oocysts. After centrifugation, lift the coverglass carefully from the centrifuge tube, place onto a glass slide, and set aside for 5-10 $\mathrm{min}$; this allows the sugar along the edges of the coverglass to harden and minimizes movement of the oocysts during observation, measurement, and photography. The coverglass should be scanned systematically $(100-400 \times)$ until oocysts are located. Measuring and detailing the structure of sporulated oocysts should always be done only under an oil immersion objective (Neofluar and Nomarski optics are both useful). Apochromatic lenses are superior to achromats and the higher the numerical aperture on the objective lens, the more accurate will be the measurements.

\section{GUIDELINES FOR DESCRIPTIONS AND SPECIES DIFFERENTIATION}

We strongly suggest that the following criteria be presented to allow accurate evaluation of a proposed new species description for coccidians (family Eimeriidae). In the list of features below, we have followed the example of Lom and Arthur (1989) by marking those features that are indispensable with a solid circle $(\bullet)$, while those recommended for inclusion are marked with an open circle ( $(0)$.

\section{The host}

(•) Make sure that the host has been reliably identified by a knowledgeable taxonomist who works with the host group and use the most up-to-date scientific name and its authority for the species.

(•) Host life stage infected (larva, juvenile, adult); this may be more important for some host groups (e.g., fish) than for others (e.g., mammals).

(•) Locality(ies) where infected hosts were collected; supply GIS coordinates whenever possible.

(•) Prevalence of infection by locality; include seasonal prevalences, if possible.

(๑) Whenever possible, deposit the actual host specimen from which the new species was described (=symbiotype specimen, see Frey et al., 1992) into an appropriate, accredited museum.

(O) Give any ecological data, habitat data, or host genetic data that may seem relevant (for examples, see Couch et al., 1993; Wilber, Hanelt, et al., 1994; Wilber, McBee, et al., 1994).

\section{The sporulated oocyst}

(•) Use only sporulated oocysts (Fig. 1) for mensural data.

(•) Supply measurements (means $[ \pm \mathrm{SD}]$ and ranges) of at least 30-50 sporulated oocysts (100 would be best) to include: oocyst length (ol), oocyst width (ow), sporocyst length (sl), sporocyst width (sw), oocyst and sporocyst length: width $(\mathrm{L}: \mathrm{W})$ ratios (Figs. 1, 3).

(•) Note characteristic features of the outer oocyst wall and any inner layers to include: rough (r) or smooth (s) outer surface texture (row, Fig. 1; sow, Fig. 2); spines or conical projections (see McAllister and Upton, 1989); and relative number of layers and approximate thickness(es).

(๑) Note presence/absence of the following structures in/on the sporulated oocyst and, if present, their size, approximate location, and a description: micropyle (m) and its width (mw, Fig. 2); micropyle cap ( $\mathrm{mc})$, its width and depth $(\mathrm{mcw} \times \mathrm{mcd}$, Fig. 2); residuum (or), its diameter and description (or, Fig. 1); polar granule(s) (pg) its/their diameter, shape (pg, Fig. 1), or if they attach in a unique manner to the inner surface of the oocyst wall (see Parker and Duszynski, 1986).

(•) Note presence/absence of the following structures in/on the sporocyst: surface features such as sporopodia (spop, Fig. 4); adhering membranes (mem, Fig. 4); ridges (see Box et al., 1980) or sutures (see Molnár, 1996); residuum (sr), its diameter and description (sr, Fig. 3); Stieda body (sb, Fig. 3 ) and associated filaments (fil, Fig. 4); substieda body (ssb, Fig. 3); and/or parastieda body (psb, Fig. 3). 


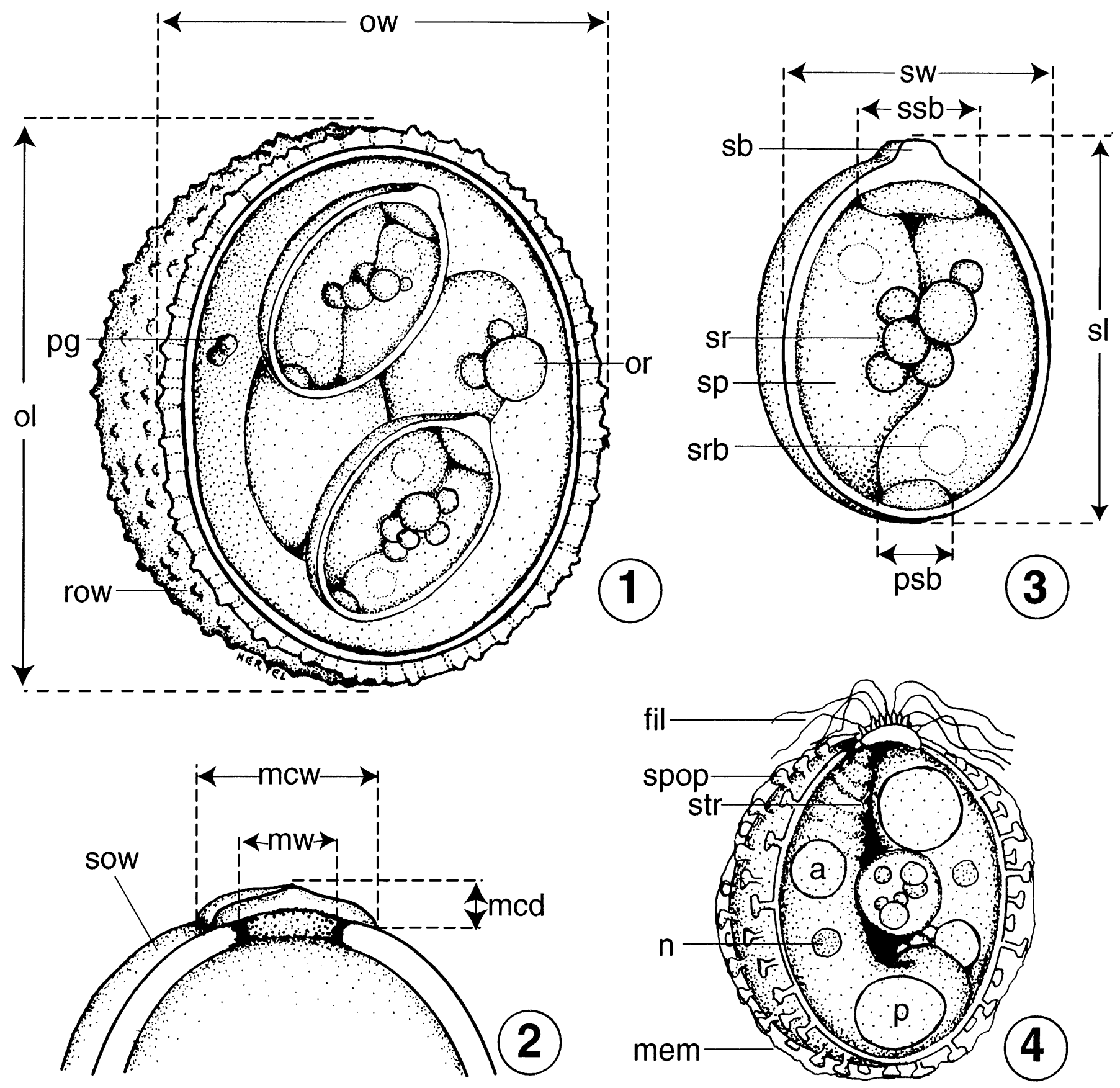

FIGURES 1-4. Line drawings of the parts of sporulated oocysts (Eimeriidae: Eimeria, Isospora, etc.) that should be measured and carefully documented when submitting a new species description for publication. 1. Sporulated oocyst of an Eimeria sp., drawn in optical cross section, showing essential structural parts that should be measured/documented in the species description: ow, oocyst width, measure the widest part when the oocyst is in good optical cross section under oil immersion; ol, oocyst length; pg, polar granule, note shape and size; or, oocyst residuum, note shape, structure, size, and whether or not it may be membrane bounded; row, rough outer wall, note this feature, if present, as well as its thickness relative to the inner wall (if present). 2. The top of an oocyst that has a micropyle, micropyle cap, and a smooth, 1-layered wall: sow, smooth outer wall; $\mathrm{mw}$, width of the micropyle; $\mathrm{mcw}$, width of the micropyle cap; mcd, depth (=height) of the micropyle cap. 3. Composite sporulated sporocyst (hypothetical) from an oocyst of Eimeria sp., drawn in optical cross section, and enlarged to show detail: sw, sporocyst width, measure the widest part when the sporocyst is in optical cross section under oil immersion; sl, sporocyst length; sb, Stieda body; ssb, substieda body, measure width and note relationship to sb (e.g., $2 \times$ wider); psb, parastieda body, measure width and height (if possible); sr, sporocyst residuum, note shape, structure, size, and whether or not it may be membrane bounded; sp, sporozoite, note any peculiar or unique features; srb, sporozoite refractile body, note size, number, and relative locations in sp. 4. Composite sporulated sporocyst (hypothetical) showing a number of unique structural features that may be present in/on the sporocysts/sporozoites of certain eimeriid species: fil, filaments eminating from the area of the Stieda body; spop, sporopodia extending from the outer surface of sporocyst wall; mem, membranouslike covering sometimes associated with sporopodia; $n$, a nucleus sometimes is visible within sporozoite; str, sporozoites sometimes have striations at their anterior end; although some sporozoites have only 1 refractile body (Fig. 3), others have both anterior (a) and posterior (p) refractile bodies as shown here. 
(•) Note presence/absence of the following structures in/on the sporozoite: refractile body (srb, Fig. 3) and its/their number, diameter, and shape; nucleus (n, Fig. 4); and other defining features such as anterior striations (str, Fig. 4), if visible.

$(\bullet)$ Deposit at least 1 phototype (see Bandoni and Duszynski, 1988) of a sporulated oocyst into an accredited or appropriate national/regional museum. In the U.S.A., these would include the United States National Parasite Museum (USNPM), Beltsville, Maryland, or the Manter Parasitology Laboratory (MPL), Lincoln, Nebraska.

(•) Provide a composite line drawing, with the new species description, that shows all of the structural features that make the new species unique; this should be drawn exactly to scale using the mean ol, ow, sl, and sw mesurements and include all distinctive structural features mentioned in the description.

(•) Be sure that the published manuscript includes at least 1 photomicrograph of a sporulated oocyst and the USNPM, MPL, or other museum accession number in addition to the composite line drawing.

(•) Minimally, the new coccidian species should be compared in detail to the coccidian species that is most structurally similar to it within the same host genus; however, it would be even better to compare it to all described species found in the host family to avoid naming a new species based solely on host species.

(O) Assuming that the collected sample of oocysts used in the species description was "pure," (i.e., had only one putative species [morphotype]), then some oocysts should be preserved in $70 \%$ ethanol and archived in an accredited museum in the event that future workers choose to amplify and sequence the parasite's DNA (Relman et al., 1996).

(O) The organ(s) and which part was infected; state if any organs were examined or whether oocysts were collected only from fecal material.

(O) Pathogenicity and histopathological observations.

\section{CONCLUDING REMARKS}

Those who describe new coccidian species based on the structure of the sporulated oocyst should be aware that many species probably are not as strictly host specific as previously thought (Duszynski, 1986; Wilber and Duszynski, unpubl.). In addition, many species occur naturally over large geographic ranges (Eimeria nieschulzi, Eimeria arizonensis), especially when hosts, (e.g., Rattus) are introduced from continent to continent through human activities or when individuals in a specious host genus (e.g., Peromyscus) have contiguous ranges across a continent. Thus, finding oocysts in a new host species or new geographic locality is not sufficient to warrant creation of a new species.

\section{ACKNOWLEDGMENTS}

This work was supported by NSF grants DEB-9505025 and DEB-9521687 to D.W.D. We are grateful to Ms. L. A. Hertel for the line drawings and Ms. B. Dennis, who helped with the computer graphics.

\section{LITERATURE CITED}

BANDONI, S. M., AND D. W. Duszynski. 1988. A plea for improved presentation of type material for coccidia. Journal of Parasitology 74: 519-523.

Box, E. D., A. A. Marchiondo, D. W. Duszynski, and C. P. Davis. 1980. Ultrastructure of Sarcocystis sporocysts from passerine birds and opossums: Comments on classification of the genus Isospora. Journal of Parasitology 66: 68-74.

Couch, L., D. W. Duszynski, AND E. Nevo. 1993. Coccidia (Apicomplexa), genetic diversity, and environmental unpredictability of four chromosomal species of the subterranean superspecies Spalax ehrenbergi (mole-rat) in Israel. Journal of Parasitology 79: 181-189.

DUSZYNSKI, D. W. 1986. Host specificity in the coccidia of small mammals: Fact or fiction? In Advances in protozoological research, $\mathrm{M}$. Bereczky (ed.). Symposia Biologica Hungarica, Vol. 33. Akademiai Kiado, Budapest, Hungary, p. 325-337.

, AND G. A. CONDER. 1977. External factors and self-regulating mechanisms which may influence the sporulation of oocysts of the rat coccidium, Eimeria nieschulzi. International Journal of Parasitology 7: 83-88.

- AND S. L. GARDNER. 1991. Fixing coccidian oocysts is not an adequate solution to the problem of preserving protozoan type material. Journal of Parasitology 77: 52-57.

Frey, J. K., T. L. Yates, D. W. Duszynski, W. L. GanNon, and S. L. GARDNER. 1992. Designation and curatorial management of type host specimens (symbiotypes) for new parasite species. Journal of Parasitology 78: 930-932.

LOM, J., AND J. R. ARTHUR. 1989. A guideline for the preparation of species descriptions in Myxosporea. Journal of Fish Diseases 12: $151-156$.

MAYR, E. 1957. Evolutionary aspects of host specificity among parasites of vertebrates. In First symposium on host specificity among parasites of vertebrates, J. G. Baer, (organizer). Institut de Zoologie, Université de Neuchátel, Neuchátel Imprimerie Paul Attinger, S.A. p. 7-14.

MCAllister, C. T., AND S. J. UPTON. 1989. The coccidia (Apicomplexa: Eimeriidae) of testudines, with descriptions of three new species. Canadian Journal of Zoology 67: 2459-2467.

MolNÁR, K. 1996. Eimerian infection in the gut of the tube-nosed goby Proterorhinus marmoratus (Pallas) of the River Danube. Systematic Parasitology 34: 43-48.

Parker, B. B., AND D. W. Duszynski. 1986. Coccidiosis of sandhill cranes (Grus canadensis) wintering in New Mexico. Journal of Wildlife Diseases 22: 25-35.

Relman, D. A., T. M. Schmidt, A. Gajadhar, M. Sogin, J. Cross, K. Yoder, O. SethabUtr, AND P. EChEVERRIA. 1996. Molecular phylogenetic analysis of Cyclospora, the human intestinal pathogen, suggests that it is closely related to Eimeria spp. The Journal of Infectious Diseases 173: 440-445.

SHEATHER, A. L. 1923. The detection of intestinal protozoa and mange parasites by a flotation technique. Journal of Comparative Pathology 36: 266-275.

UPTON, S. J., S. L. GARDNER, AND D. W. Duszynski. 1988. The round stingray, Urolophus halleri (Rajiformes: Dasyatidae), as a host for Eimeria chollaensis sp. nov. (Apicomplexa: Eimeriidae). Canadian Journal of Zoology 66: 2049-2052.

Wash, C. D., D. W. Duszynski, AND T. L. Yates. 1985. Eimerians from different karyotypes of the Japanese wood mouse (Apodemus spp.), with descriptions of two new species and a redescription of Eimeria montgomeryae Lewis and Ball, 1983. Journal of Parasitology 71: 808-814.

Wilber, P. G., B. Hanelt, B. Van Horne, and D. W. Duszynski. 1994. Two new species and temporal changes in the prevalence of eimerians in a free-living population of Townsend's ground squirrels (Spermophilus townsendii) in Idaho. Journal of Parasitology 80: 251-259.

, K. McBee, D. J. Hafner, and D. W. DuszynsKi. 1994. A new coccidian (Apicomplexa: Eimeriidae) in the northern pocket gopher (Thomomys talpoides) and a comparison of oocyst survival in hosts from radon-rich and radon-poor soils. Journal of Wildlife Diseases 30: 359-364. 